\title{
Desain dan Analisis Kekuatan Rangka Tricycle Landing Gear UAV Menggunakan Metode Elemen Hingga
}

\author{
Lasinta Ari Nendra Wibawa \\ Balai Uji Teknologi dan Pengamatan Antariksa dan Atmosfer \\ Lembaga Penerbangan dan Antariksa Nasional (LAPAN) \\ Jln. Cilauteureun, Cikelet, Garut 44177 \\ Telp.: (0262) 521282, Fax: (0262) 521282 \\ E-mail: lasinta.ari@lapan.go.id
}

\begin{abstract}
This study examined the design and analysis of tricycle landing gear frame strength using the finite element method. Linear static analysis was carried out using Autodesk Inventor Professional 2017. The landing gear frame material used Aluminum 6061. Variable vertical landing speeds were $4 \mathrm{~m} / \mathrm{s}, 6 \mathrm{~m} / \mathrm{s}, 8 \mathrm{~m} / \mathrm{s}$, and $10 \mathrm{~m} / \mathrm{s}$. Simulation results show that the landing gear frame is safe enough to withstand landing speeds of up to $8 \mathrm{~m} / \mathrm{s}$ because it has a safety factor of 2.32 .
\end{abstract}

Keywords: aluminum 6061, autodesk inventor 2017, finite element analysis, landing gear, strength analysis

\begin{abstract}
Abstrak
Penelitian ini mengkaji tentang desain dan analisis kekuatan rangka tricycle landing gear menggunakan metode elemen hingga. Analisis statik linear dilakukan menggunakan software Autodesk Inventor Professional 2017. Material rangka landing gear menggunakan Aluminium 6061. Variabel kecepatan landing vertikal yaitu 4 $\mathrm{m} / \mathrm{s}, 6 \mathrm{~m} / \mathrm{s}, 8 \mathrm{~m} / \mathrm{s}$, dan $10 \mathrm{~m} / \mathrm{s}$. Hasil simulasi menunjukkan bahwa rangka tricycle landing gear cukup aman untuk menahan kecepatan landing hingga $8 \mathrm{~m} / \mathrm{s}$ karena memiliki faktor keamanan sebesar 2,32.
\end{abstract}

Kata kunci: aluminium 6061, autodesk inventor 2017, analisis elemen hingga, landing gear, analisis kekuatan

\section{PENDAHULUAN}

Sekarang ini UAV (Unmanned Aerial Vehicle) atau Drone telah digunakan di berbagai aplikasi seperti industri militer, transportasi kargo komersial, dan pemetaan [1]. Pesawat UAV juga sering digunakan dalam berbagai misi penyelamatan dan mitigasi bencana saat terjadi bencana letusan gunung berapi, banjir, tanah longsor, dan gempa bumi karena cukup efisien dan aman.

Landing gear adalah struktur pendukung utama pesawat saat mendarat (landing) dan lepas landas (take off). Landing gear terdiri dari 3 (tiga) roda: 2 (dua) roda utama, dan 1 (satu) roda di depan atau di belakang pesawat.

Landing gear ada beberapa jenis, yaitu tailwheel, tandem, dan tricycle. Tricycle landing gear adalah landing gear yang terdiri dari 2 (dua) roda utama pada bagian tengah yang merupakan pendukung beban UAV dan 1 (satu) roda pada bagian depan atau hidung pesawat yang berfungsi untuk mengontrol manuver dari pesawat.

Tricycle landing gear adalah jenis yang paling banyak digunakan pada pesawat UAV karena distribusi beban UAV lebih merata sehingga jauh lebih stabil dan aman, tidak terpengaruh lintasan angin yang melintang, mengurangi bising saat pengereman, dan meminimalkan terjadinya groundlooping.

Penelitian ini bertujuan merancang rangka tricycle landing gear dengan material Aluminium paduan 6061 yang merupakan material yang memiliki sifat ringan, titik cair rendah, dan tahan korosi. Material Aluminium 6061 juga memiliki kekuatan luluh (yield strength) yang cukup tinggi, yaitu sebesar $275 \mathrm{MPa}$.

\section{METODE}

\section{Perangkat lunak (Software)}

Penelitian ini menggunakan simulasi perangkat lunak (software) Autodesk Inventor Professional 2017. Simulasi Autodesk Inventor berguna untuk menjalankan analisis untuk membuktikan validitas dari sebuah desain. Hal ini jauh lebih praktis dan hemat waktu saat merancang desain sebelum membuatnya dalam bentuk prototipe fisik [2].

Autodesk Inventor Professional adalah salah satu produk dari Autodesk Inc. USA yang dulu lebih familier dengan produk AutoCAD [3]. Analisis tegangan yang dilakukan oleh Autodesk Inventor menggunakan metode analisis elemen hingga. Analisis elemen hingga adalah teknik numerik 
matematis untuk menghitung kekuatan dan perilaku struktur komponen teknik dengan membagi obyek menjadi bentuk jala (mesh).

Asumsi pada saat melakukan analisis linier, yaitu [2]:

1. Sifat material komponen tetap linier setelah batas luluh. Maka, hasil diluar batas luluh tidak valid menggunakan simulasi Autodesk Inventor.

2. Defleksi komponen sangat kecil dibandingkan ukuran komponen secara keseluruhan.

3. Komponen bersifat kaku dan ulet. Misalnya, material logam (bukan karet).

4. Deformasi komponen sama dalam ketiga arah. Dengan kata lain, material bersifat isotropik.

Dimensi rangka landing gear secara detail ditunjukkan pada Gambar 1.

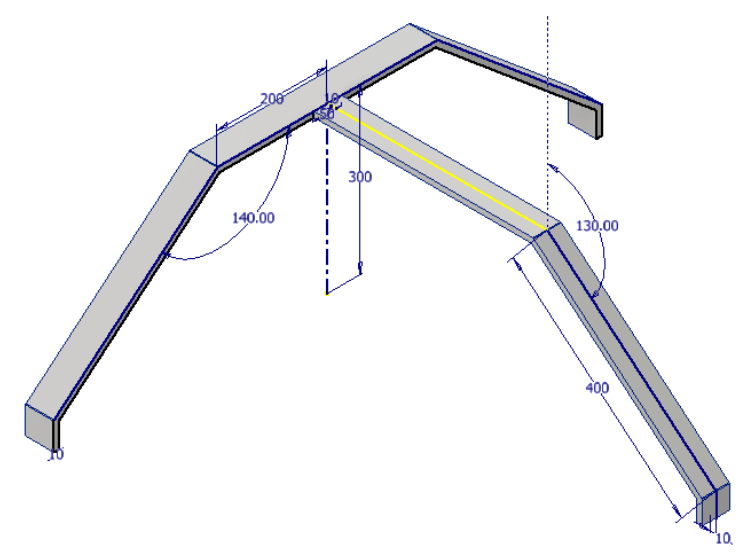

Gambar 1. Desain 3 (tiga) dimensi landing gear (dalam mm)

Karena beban impak adalah fungsi dari kecepatan vertikal, maka persamaan momentum impulsnya adalah:

$F \Delta t=m V_{f}$

Dimana:

$F=$ beban impak

$\Delta t=$ waktu impak

$m$ = massa pesawat UAV

$V_{f}=$ kecepatan landing vertikal

Dengan menggunakan asumsi bahwa kecepatan vertikal saat landing, massa, dan waktu impak dari UAV serta parameter analisis tegangan menggunakan Autodesk Inventor Professional 2017 dijabarkan secara lengkap pada Tabel 1 berikut ini.

Tabel 1. Asumsi dan parameter analisis tegangan

\begin{tabular}{ll}
\hline Tipe Simulasi & Single Point \\
\hline Variabel kecepatan & $\begin{array}{l}4 \mathrm{~m} / \mathrm{s}, 6 \mathrm{~m} / \mathrm{s}, 8 \mathrm{~m} / \mathrm{s} \text {, dan } 10 \\
\mathrm{~m} / \mathrm{s}\end{array}$ \\
\hline Massa UAV & $75 \mathrm{~kg}$ \\
\hline Waktu impak & 0,5 detik
\end{tabular}

\begin{tabular}{ll}
\hline Beban impak & $\begin{array}{l}600 \mathrm{~N}, 900 \mathrm{~N}, 1200 \mathrm{~N}, \text { dan } \\
1.500 \mathrm{~N}\end{array}$ \\
\hline $\begin{array}{l}\text { Average element } \\
\text { size }\end{array}$ & $0,1 \mathrm{~mm}$ \\
\hline $\begin{array}{l}\text { Minimum element } \\
\text { size }\end{array}$ & $0,2 \mathrm{~mm}$ \\
\hline Safety factor & Berdasarkan yield strength \\
\hline Jumlah node & 2559 \\
\hline Jumlah elemen & 1100 \\
\hline
\end{tabular}

\section{HASIL DAN PEMBAHASAN}

Tabel 2 menunjukkan sifat fisik material Aluminium paduan 6061. Material Aluminium 6061 memiliki massa jenis sebesar $2,7 \mathrm{gram} / \mathrm{cm}^{3}$. Hal ini berdampak pada massa total rangka landing gear yang cukup ringan, yaitu hanya seberat $2,83 \mathrm{~kg}$.

Tabel 2. Sifat fisik material landing gear

\begin{tabular}{ll}
\hline Parameter & Keterangan \\
\hline Material & Aluminum 6061 \\
\hline Density & $2,7 \mathrm{~g} / \mathrm{cm}^{3}$ \\
\hline Mass & $2,83 \mathrm{~kg}$ \\
\hline Area & $252433 \mathrm{~mm}^{2}$ \\
\hline Volume & $1047940 \mathrm{~mm}^{3}$ \\
\hline Yield Strength & $275 \mathrm{MPa}$ \\
\hline Ultimate Tensile Strength & $310 \mathrm{MPa}$ \\
\hline Young's Modulus & $68,9 \mathrm{GPa}$ \\
\hline Poisson's Ratio & $0,33 \mathrm{ul}$ \\
\hline Shear Modulus & $25,90 \mathrm{GPa}$ \\
\hline
\end{tabular}

Hasil simulasi Autodesk Inventor menggunakaan analisis statik linier. Analisis statik adalah disiplin teknik yang menentukan tegangan pada material dan struktur yang mengalami gaya atau beban statis maupun dinamis [4]. Analisis statik menggunakan metode elemen hingga bertujuan untuk menentukan struktur atau komponen, dapat dengan aman menahan kekuatan dan beban yang telah ditentukan. Kondisi ini dapat tercapai saat tegangan yang ditentukan dari gaya yang diaplikasikan kurang dari kekuatan luluh material dalam menahan beban. Hubungan tegangan ini sering disebut sebagai faktor keamanan (safety factor) dan digunakan dalam banyak analisis sebagai indikator keberhasilan atau kegagalan dalam sebuah analisis [2].

Gambar 3, Gambar 4, Gambar 5, dan Gambar 6 menunjukkan hasil simulasi tegangan von Mises rangka tricycle landing gear terhadap variasi kecepatan vertical pesawat UAV. Tegangan von Mises maksimal rangka tricycle landing gear terhadap kecepatan landing $4 \mathrm{~m} / \mathrm{s}, 6 \mathrm{~m} / \mathrm{s}, 8 \mathrm{~m} / \mathrm{s}$, dan $10 \mathrm{~m} / \mathrm{s}$ berturut-turut sebesar 59,2 MPa, 88,79 MPa, 118,4 MPa, dan $148 \mathrm{MPa}$. Tegangan von Mises masih berada di bawah kekuatan luluh (yield strength) material Aluminium 6061, yaitu sebesar $275 \mathrm{MPa}$. 


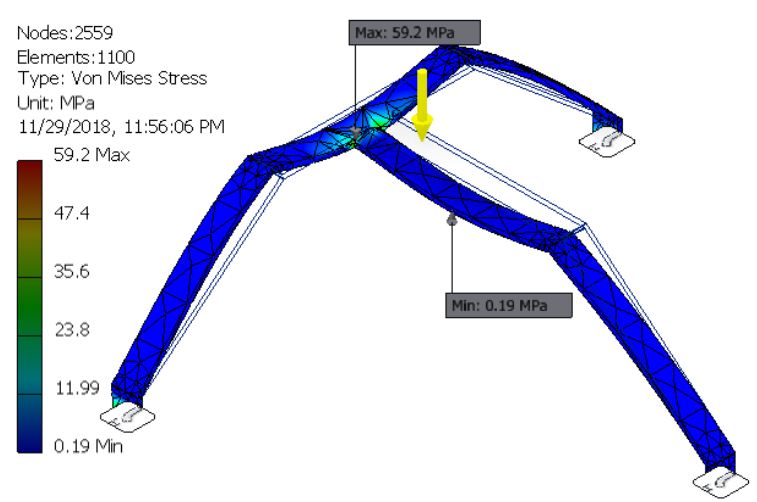

Gambar 3. Tegangan von mises pada kecepatan landing $4 \mathrm{~m} / \mathrm{s}$.

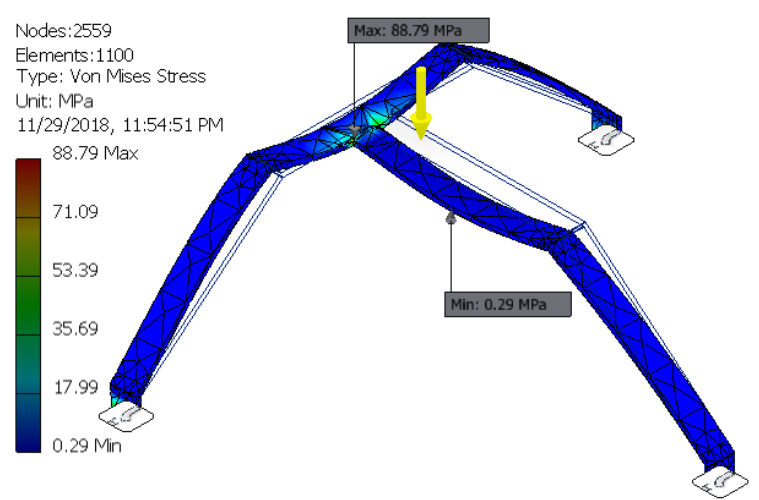

Gambar 4. Tegangan von mises pada kecepatan landing $6 \mathrm{~m} / \mathrm{s}$.

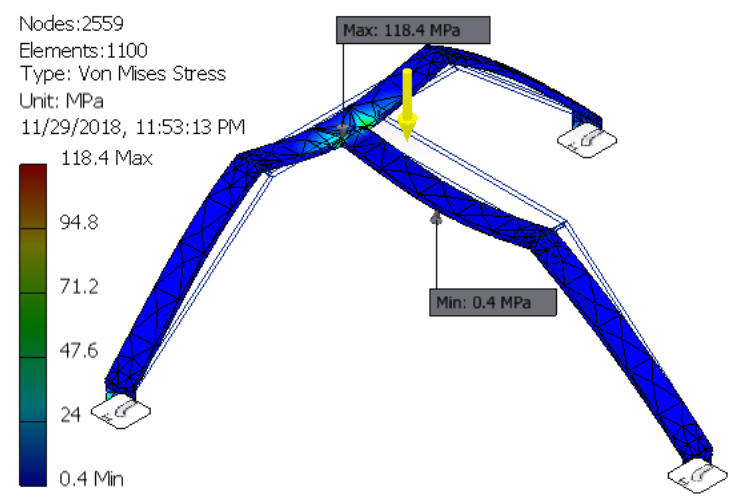

Gambar 5. Tegangan von mises pada kecepatan landing $8 \mathrm{~m} / \mathrm{s}$.

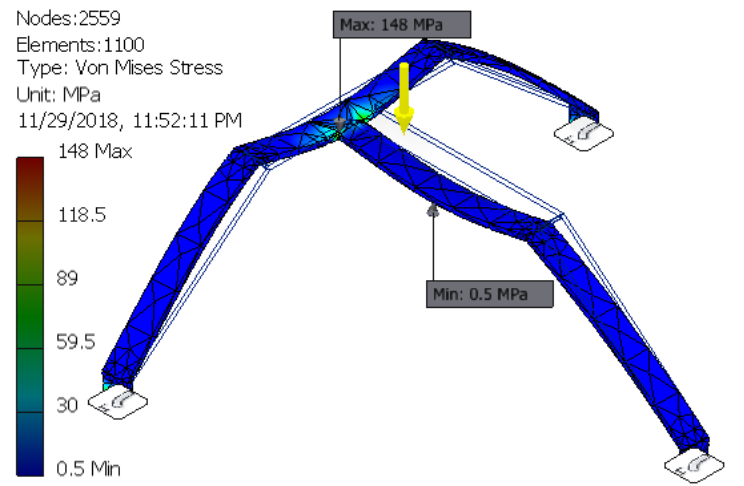

Gambar 6. Tegangan von mises pada kecepatan landing $10 \mathrm{~m} / \mathrm{s}$.

Gambar 7, Gambar 8. Gambar 9, dan Gambar 10 menunjukkan nilai deformasi (displacement) material terhadap kecepatan landing pesawat UAV. Nilai deformasi maksimal rangka landing gear terhadap kecepatan vertikal $4 \mathrm{~m} / \mathrm{s}, 6 \mathrm{~m} / \mathrm{s}, 8 \mathrm{~m} / \mathrm{s}$, dan $10 \mathrm{~m} / \mathrm{s}$ berturut-turut sebesar $1,296 \mathrm{~mm}, 1,944 \mathrm{~mm}$, 2,592 $\mathrm{mm}$, dan 3,240 $\mathrm{mm}$. Nilai deformasi ini relatif cukup kecil.

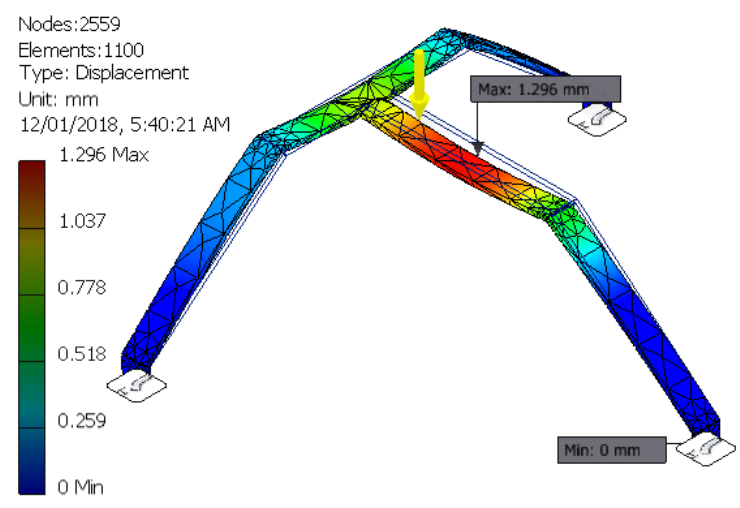

Gambar 7. Deformasi pada kecepatan landing $4 \mathrm{~m} / \mathrm{s}$.

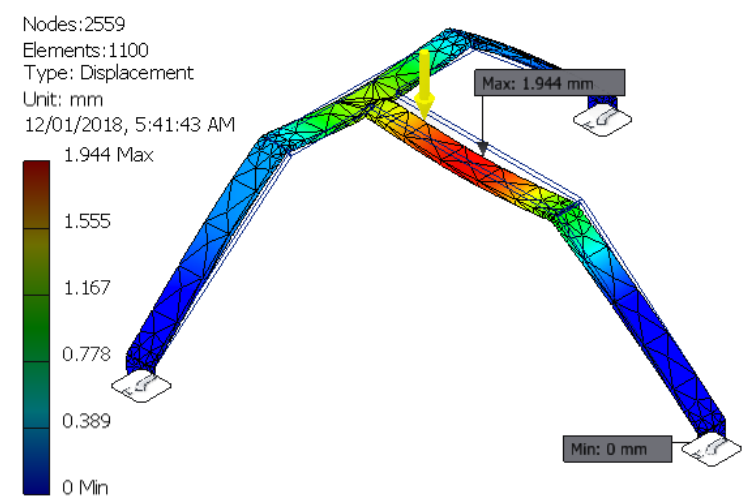

Gambar 8. Deformasi pada kecepatan landing $6 \mathrm{~m} / \mathrm{s}$. 


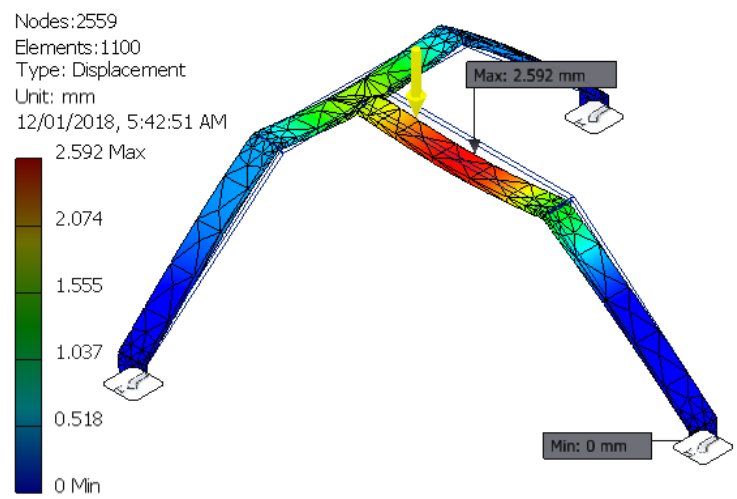

Gambar 9. Deformasi pada kecepatan landing $8 \mathrm{~m} / \mathrm{s}$.

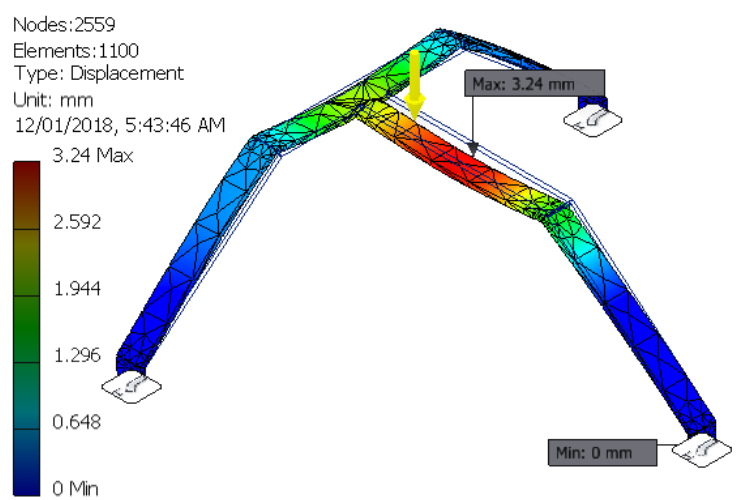

Gambar 10. Deformasi pada kecepatan landing 10 $\mathrm{m} / \mathrm{s}$.

Gambar 11, Gambar 12, Gambar 13, dan Gambar 14 menunjukkan nilai faktor kemanan (safety factor) material terhadap variasi kecepatan landing pesawat UAV. Nilai faktor keamanan (safety factor) minimum pada saat kecepatan landing $4 \mathrm{~m} / \mathrm{s}$, $6 \mathrm{~m} / \mathrm{s}, 8 \mathrm{~m} / \mathrm{s}$, dan $10 \mathrm{~m} / \mathrm{s}$ berturut-turut sebesar 4,65, $3,10,2,32$, dan 1,86 .

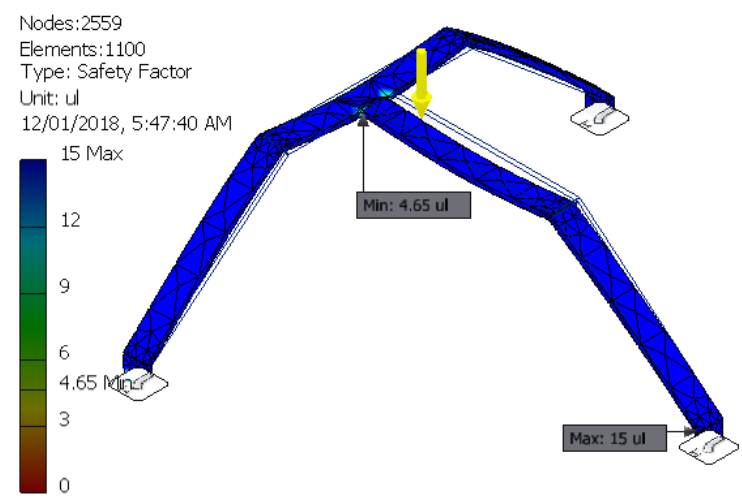

Gambar 11. Faktor keamanan pada kecepatan landing $4 \mathrm{~m} / \mathrm{s}$.

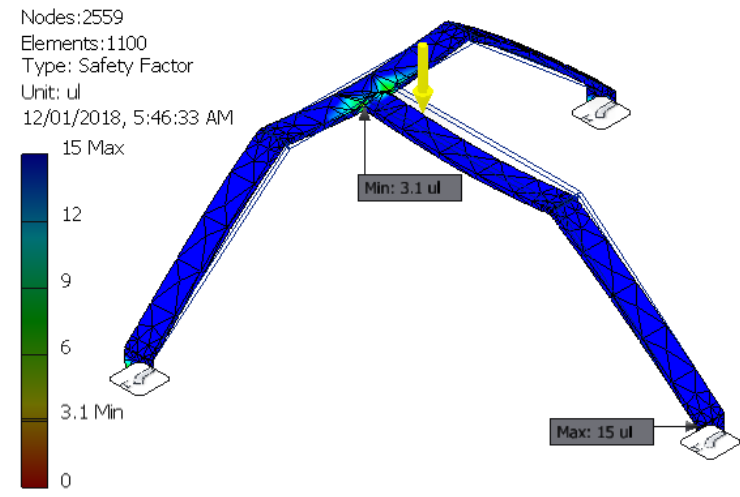

Gambar 12. Faktor keamanan pada kecepatan landing $6 \mathrm{~m} / \mathrm{s}$.

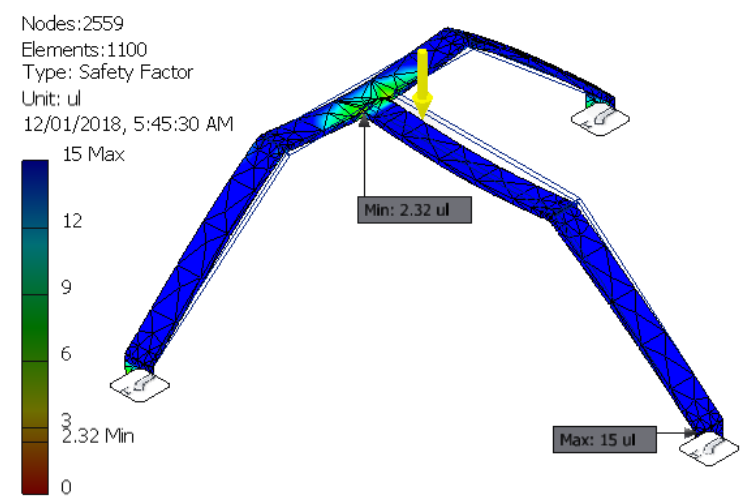

Gambar 13. Faktor keamanan pada kecepatan landing $8 \mathrm{~m} / \mathrm{s}$.

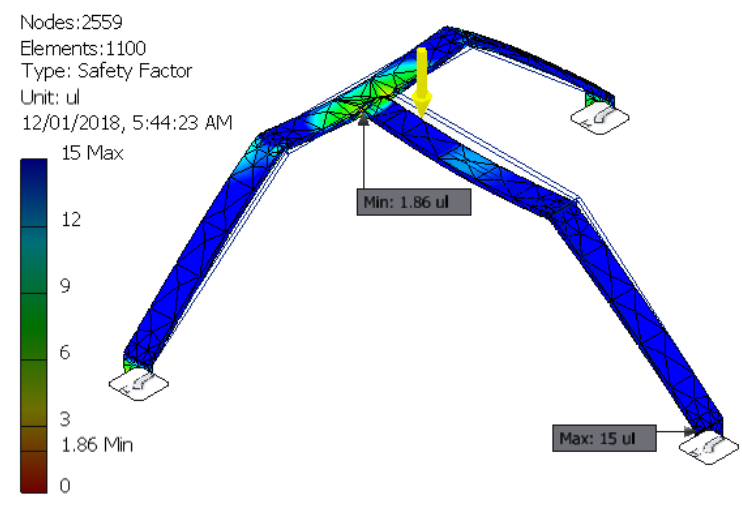

Gambar 14. Faktor keamanan pada kecepatan landing $10 \mathrm{~m} / \mathrm{s}$.

Nilai faktor keamanan (safety factor) pada saat kecepatan $10 \mathrm{~m} / \mathrm{s}$ berada di bawah standar yang dipersyaratkan untuk suatu komponen mampu menahan beban dinamis. Beban dinamis adalah beban yang dapat terjadi atau bekerja secara tiba-tiba pada sebuah struktur. Beban dinamis umumnya kecil tetapi berubah-ubah terhadap waktu [5]. Beban dinamis dapat berupa beban angin, beban seismik, beban fatigue, dan frekuensi natural. Beban dinamis perlu diantisipasi karena rangka landing gear kerap mengalami getaran dan beban impak fluktuatif yang 
dihasilkan dari variasi kecepatan landing pesawat UAV. Nilai safety factor yang dipersyaratkan untuk suatu komponen mampu menahan beban dinamis yaitu pada kisaran angka 2-3 [6].

Hasil simulasi rangka landing gear secara lengkap dapat dilihat pada Tabel 3. Hasil simulasi menunjukkan rancangan rangka landing gear masih cukup aman untuk menahan beban impak yang dihasilkan dari kecepatan landing hingga $8 \mathrm{~m} / \mathrm{s}$. Hal ini karena nilai safety factor sebesar 2,32.

Tabel 3. Hasil simulasi tegangan

\begin{tabular}{|c|c|c|c|}
\hline $\begin{array}{c}\text { Kecepatan } \\
(\mathrm{m} / \mathrm{s})\end{array}$ & $\begin{array}{c}\text { Tegangan von } \\
\text { Mises }(\mathrm{MPa})\end{array}$ & $\begin{array}{c}\text { Deformasi } \\
(\mathrm{mm})\end{array}$ & $\begin{array}{c}\text { Safety } \\
\text { factor }\end{array}$ \\
\hline 4 & 59,2 & 1,296 & 4,65 \\
\hline 6 & 88,79 & 1,944 & 3,10 \\
\hline 8 & 118,4 & 2,592 & 2,32 \\
\hline 10 & 148 & 3,240 & 1,86 \\
\hline
\end{tabular}

\section{KESIMPULAN}

Desain rangka landing gear menggunakan material Aluminium 6061 memiliki massa yang yang cukup ringan, yaitu sebesar $2,83 \mathrm{~kg}$. Rancangan rangka landing gear yang telah dibuat cukup aman untuk menahan kecepatan landing hingga $8 \mathrm{~m} / \mathrm{s}$. Hal ini karena nilai faktor keamanannya sebesar 2,32.

\section{DAFTAR PUSTAKA}

[1] J. Parmar and V. Acharya, "Selection and Analysis of the Landing Gear for Unmanned Aerial Vehicle for Sae Aero Design Series," Int. J. Mech. Eng. Technol., vol. 6, no. 2, pp. 10-18, 2015.

[2] L. A. N. Wibawa, Simulasi Kekuatan Komponen Sarana Pengujian Roket Menggunakan Autodesk Inventor Professional 2017. Buku Katta, 2018.

[3] L. A. N. Wibawa, Merancang Komponen Roket $3 D$ dengan Autodesk Inventor Professional 2017. Buku Katta, 2018.

[4] W. Younis, Up and running with Autodesk Inventor Simulation 2011: a step-by-step guide to engineering design solutions. Elsevier, 2010.

[5] L. A. N. Wibawa and D. A. Himawanto, "Analisis Ketahanan Beban Dinamis Material Turbin Angin Terhadap Kecepatan Putar Rotor (Rpm) Menggunakan Metode Elemen Hingga," J. Simetris, vol. 9, no. 2, pp. 803-808, 2018.

[6] K. Z. V. Dobrovolsky, Machine elements : a textbook. Moscow: Peace Publisher, 1978. 